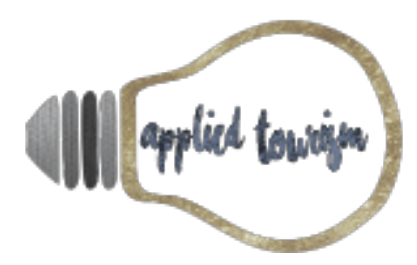

Volume 3, número 3, 2018, p. 37- 53

\title{
FEIRA DO PEIXE VIVO: Feiras Rurais enquanto Alternativa para a Agricultura Familiar e o Desenvolvimento Rural Sustentável.
}

\author{
Raphael Miranda Medeiros Cruz, \\ Mestrando em Desenvolvimento Rural Sustentável \\ Universidade Estadual do Oeste do Paraná, Campus Marechal Candido Rondon \\ Professor do Instituto Federal do Paraná, IFPR \\ raphael.cruz@ifpr.edu.br \\ Rosislene de Fátima Fontana \\ Doutora em Turismo e Hotelaria pela UNIVALI \\ Professora colaboradora do Mestrado em Desenvolvimento Rural Sustentável \\ Universidade Estadual do Oeste do Paraná, Campus Marechal Candido Rondon \\ rosislene.fontana@unioeste.br
}

Recebido: 13 de setembro, 2018 Aprovado: 17 de outubro, 2018

\section{RESUMO}

O turismo como alternativa para desenvolvimento rural sustentável descobriu que as feiras rurais fortalecem os laços entre o urbano e rural, e o sujeito principal o produtor rural através da agricultura familiar encontra uma grande oportunidade de fortalecimento econômico no mercado local. Este artigo tem por objetivo analisar a Feira do Peixe Vivo enquanto propulsora do desenvolvimento rural sustentável em Foz do Iguaçu-PR. Trata-se de um estudo exploratório descritivo, com pesquisa bibliográfica e documental, complementado por pesquisa de campo com aplicação de questionário estruturado com perguntas fechadas, utilizando-se da escala Likert junto aos expositores rurais. Como principal resultado observado, tem-se a Feira do Peixe Vivo como um evento consolidado em Foz do Iguaçu, servindo de alternativa de negócio para a agricultura familiar e o turismo rural, agindo como propulsor do desenvolvimento rural sustentável no município.

Palavras-chaves: Feiras Rurais. Feira do Peixe Vivo. Desenvolvimento Rural Sustentável. 


\section{INTRODUÇÃO}

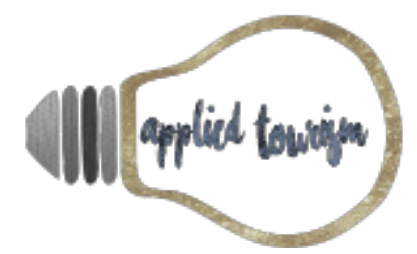

Volume 3, número 3, 2018, p. 37- 53

$\mathrm{Na}$ atualidade, a atividade turística tem um impacto direto no crescimento e desenvolvimento das sociedades, sendo impulsionada, entre outros aspectos, pelos avanços sociais e as novas tecnologias que possibilitaram melhorias nos transportes, comunicações e na administração desses sistemas (Nagildo \& Fontana, 2016).

Em meio às diversas formas de turismo disponibilizadas para o lazer, entretenimento e descanso do turista, têm-se percebido um crescente interesse pela atividade turística localizada no meio rural. Essa tendência aparece para os produtores rurais como uma oportunidade de agregar valor a seus negócios, sendo muitas vezes responsável por um aumento das oportunidades de trabalho no campo e permitindo uma maior oportunidade de emprego e renda para os habitantes das zonas rurais (Fontana \& Dencker, 2006, p. 2).

O município de Foz do Iguaçu está localizado no Oeste do Paraná e tem sua economia voltada para o turismo, geração de energia, comércio e agricultura. No município predomina-se a agricultura de pequena propriedade e familiar. Os principais cultivos praticados são: soja, milho, trigo, mandioca, fruticultura, produção leiteira, pequenos animais, aves e piscicultura. Esta mesma agricultura familiar é responsável por cerca de $40 \%$ de toda produção agrícola no Município (Secretaria de Agricultura de Foz do Iguaçu, 2018). Nos últimos anos a agricultura familiar tem buscado alternativas para a comercialização de seus produtos, e encontrou na atividade turística, através de feiras e eventos uma opção para o incremento de sua renda.

Nesta abordagem, este artigo propõe uma análise dos eventos rurais enquanto propulsores do desenvolvimento rural sustentável, mais precisamente sobre a Feira do Peixe Vivo, realizada em de Foz do Iguaçu, uma vez que este evento rural, embora em espaço urbano, é o principal do município, de acordo com a Secretaria Municipal de Agricultura.

Considerando ainda que novas possibilidades se abrem para serem exploradas pela agricultura familiar, seus produtos tem condições de ocupar maiores espaços no mercado local, nacional e internacional, beneficiando-se de valores que sejam agregados aos produtos (Flores, 2002).

Com as modificações nas formas de produção e relação social ocorridas no meio rural brasileiro principalmente a partir da década de 1980, opções de atividades alternativas no campo foram necessárias para a complementação da renda (Geogin \& Scherer, 2015). O turismo rural, por intermédio das festas e feiras rurais, surge como uma opção de atividade não agrícola e no nosso objeto de pesquisa, uma alternativa para o produtor escoar sua produção sem intermediários, garantindo melhores retornos financeiros. 


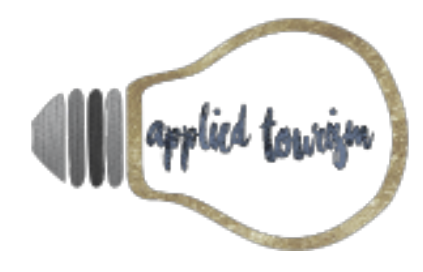

Volume 3, número 3, 2018, p. 37- 53

No caso das festas e feiras rurais, além do visitante entrar em contato com a cultura local, a população pode valorizar a qualidade dos produtos oferecidos na feira e conseguir preços melhores que em centros de distribuições alimentícios.

Com este propósito, o objetivo central desta investigação é analisar a Feira do Peixe vivo enquanto propulsor do desenvolvimento rural sustentável no município de Foz do Iguaçu-PR.

\section{METODOLOGIA}

Este artigo caracteriza-se como um estudo exploratório descritivo, com pesquisa bibliográfica e documental, complementado por pesquisa de campo com aplicação de questionários aos expositores rurais.

Inicialmente realizou-se uma revisão bibliográfica e documental nas principais referências para a caracterização do tema, pois segundo Fortin (1996), a revisão da literatura é um processo que consiste em fazer o inventário e o exame crítico do conjunto de publicações pertinentes sobre o domínio de investigação. Neste caso, buscou-se material sobre o Desenvolvimento Rural e Sustentabilidade, Agricultura Familiar, Turismo Rural e Feiras Rurais. Complementando esta fase da pesquisa, realizou-se a busca documental das informações extraídas do acervo documental da Secretaria Municipal da Agricultura sobre a Feira do Peixe Vivo, realizada no município de Foz do Iguaçu, desde sua criação até a edição de 2018.

Para Gil (2002), as pesquisas exploratórias proporcionam uma maior intimidade com o problema, com o objetivo de clarificá-lo, além de apresentar menor rigidez de planejamento pela característica de revelar uma visão mais ampla sobre o determinado fato. Ainda sobre a pesquisa descritiva, Gil (2002) expõe que seu principal objetivo é relatar características de determinada população, amostra ou fenômeno, ou ainda estabelecer relações sobre variáveis, utiliza-se técnicas padronizadas de coletas de dados como questionário e observação sistêmica.

Para tanto, como instrumento para a coleta de dados, criou-se um questionário estruturado com perguntas fechadas, aplicado aos expositores rurais presentes na edição de 2018, dividido em dois blocos, sendo o primeiro a caracterização do respondente e o segundo, perguntas relativas à Feira do Peixe Vivo propriamente dita, por meio de cinco constructos visando analisar a participação das organizações públicas e privadas no auxílio na organização e gestão do evento, as dimensões ambiental, econômica e social do evento e ainda, os produtos comercializados, com intuito de estabelecer a relação das feiras rurais como proposta alternativa para a agricultura familiar e consequentemente, propulsora do desenvolvimento rural sustentável no município de Foz do Iguaçu. 


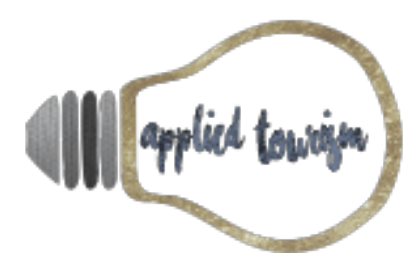

Volume 3, número 3, 2018, p. 37- 53

Quadro 01 - Escala utilizada no questionário aplicado aos expositores

\begin{tabular}{|l|l|}
\hline Escala do Grau de Importância & Escala do Grau de Implementação \\
\hline $1=$ nada importante & $1=$ nada implementado \\
$2=$ pouco importante & $2=$ pouco implementado \\
$3=$ medianamente importante & $3=$ medianamente implementado \\
$4=$ bastante importante & $4=$ bastante implementado \\
$5=$ extremamente importante & $5=$ totalmente implementado \\
\hline
\end{tabular}

Fonte: Elaboração própria (2018).

Tal questionário, em seu segundo bloco utilizou-se de respostas buscando a importância e implementação dos constructos estudados, por meio da utilização da escala Likert, com valores de 1 à 5, onde o entrevistado estabeleceu o grau de importância percepcionado para os itens mencionados, bem como para o grau de implementação de cada constructo enquanto propulsor do desenvolvimento rural sustentável.

\section{FUNDAMENTAÇÃO TEÓRICA}

A história tem evidenciado que a ideia de desenvolvimento tem uma força mobilizadora que não pode ser subestimada. Em nome do desenvolvimento lideranças mobilam grupos, municípios, nações ou continentes (Froehlich \& Diesel, 2006). Em seu nome também as propriedades justificam suas prioridades e, em função de uma visão econômica onde se visa o lucro e crescimento, beneficiam-se a alguns e prejudicam-se a outros.

O desenvolvimento humano requer que se removam as principais fontes de privações de liberdade, como pobreza, tirania, carência de oportunidades e destruição sistemática do social (Sem, 2008). Na economia global, dominada por grandes centros urbanos que concentram grande parte da população e das atividades econômicas, existe uma vasta extensão geográfica de territórios rurais. Apesar das áreas rurais apresentarem duas características distintas que se diferenciam: o grande produtor com pouca diversificação de plantio e voltado exclusivamente para o desenvolvimento econômico e, o pequeno agricultor (agricultura familiar) que apresenta diversidade de produção. Assim, nestes territórios, a qualidade de vida das populações bem como as perspectivas de desenvolvimento econômico são bastante reduzidas, o que a médio e longo prazo, pode resultar no seu abandono e venda da propriedade (Sem, 2008).

Nestas condições, Souza e Elesbão (2011) sugerem que as razões para desenvolver um território rural viável envolvem aspectos ambientais, socioculturais e econômicos. Esses aspectos incluem garantia e fiabilidade dos alimentos produzidos, preservação dos recursos naturais e a biodiversidade e, principalmente, uma matriz cultural própria e distinta das matrizes tendencialmente globalizadoras das áreas mais urbanas. Os fins e os meios do desenvolvimento requerem análise minuciosa para uma compreensão mais plena sendo inadequado afirmar 


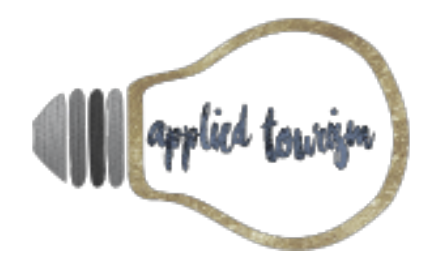

Volume 3, número 3, 2018, p. 37- 53

como objetivo básico a maximização da renda ou da riqueza; o desenvolvimento deve estar relacionado com a melhora de vida e principalmente o desfrute de liberdade (Sem, 2008).

Neste sentido, a valorização da atividade turística como uma estratégia do desenvolvimento rural foi adotada no Brasil desde o início dos anos 1990, e se deu, principalmente, em razão da necessidade de buscar novas alternativas na promoção da melhoria das condições sociais e econômicas do campo. Desta forma, para Souza e Elesbão (2011), o turismo no espaço rural busca dinamizar a economia das pequenas propriedades rurais e preservando o patrimônio cultural daquela população. Mais precisamente as festas e feiras rurais determinam o patrimônio da população rural, despertando o interesse dos agentes promotores do desenvolvimento, dos gestores municipais e pesquisadores. As festas rurais são democráticas, são entendidas como um código sociocultural e simbólico impresso e produzido no espaço geográfico (Souza \& Elesbão, 2011).

Segundo Flores (2002, p.347) o fortalecimento como expressão social, econômica e política, significa rediscutir o modelo de desenvolvimento do mundo rural, com todos os seus impactos sobre a área urbana. Sendo a produção familiar a principal atividade econômica de diversas regiões brasileiras, esta precisa ser fortalecida, pois o potencial dos agricultores familiares na geração de empregos e renda é muito importante. É preciso garantir a eles acesso a credito, condições e tecnologias para a produção e para manejo sustentável de seus estabelecimentos, além de garantias para a comercialização de seus produtos agrícolas (Lima \& Ilkinson, 2002).

Surge, portanto, como alternativa, o meio rural ser um espaço diferenciado, não mais apenas um lugar de produção agropecuária, como também, de ser espaço para formas de lazer ligadas ao contato com a natureza (Wanderley, 2002). Para Carneiro (2005), é a vez da cidade se voltar para o campo, seja através do deslocamento físico, possibilitado pela facilidade de acesso aos locais rurais, bem como a intercomunicação de valores e da expansão do sistema viário, como da intercomunicação de valores, símbolos e práticas pertencentes a universos culturais distintos. Sendo assim, o turismo rural é uma atividade que deve ser vista e entendida como sendo um complemento às atividades agrícolas das propriedades rurais, de tal forma que o cotidiano da vida rural, em menor ou maios intensidade, continue a existir (Fontana \& Denker, 2006).

No contexto do turismo no espaço rural, surgem as feiras comerciais. As feiras oferecem a oportunidade de comércio em escala crescente, que propicia o desenvolvimento das atividades produtivas, estabelecendo as redes entre produtores e consumidores (Matias, 2001). Sendo assim, tem-se nas feiras o fomento da atividade comercial impulsionada pelo turismo de eventos e, mais precisamente no meio rural, servindo muitas vezes de oportunidade de escoamento da produção agrícola e garantia de incremento da renda para agricultores familiares. 


\section{RESULTADOS E DISCUSSÕES}

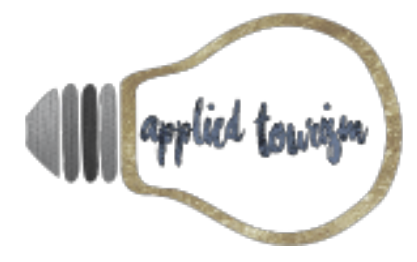

Volume 3, número 3, 2018, p. 37- 53

A seguir serão apresentados os dados referentes à pesquisa realizada, no tocante ao levantamento histórico da Feira do Peixe Vivo de Foz do Iguaçu, de acordo com informações fornecidas pela Secretaria Municipal de Agricultura, bem como com relação à pesquisa realizada junto aos expositores rurais presentes na edição de 2018.

\section{HISTÓRICO DA FEIRA DO PEIXE VIVO}

O evento foi criado em 2005, junto com o surgimento da Secretaria de Agricultura do município de Foz do Iguaçu e atualmente é caracterizado como o principal evento da agricultura rural do município, tendo como intuito estimular a produção e consumo de pescados. Esta feira sempre é realizada na Semana Santa e conta com a participação dos produtores da agricultura familiar, artesãos, donos de pesque-pague, piscicultores e principalmente, pescadores registrados na colônia Z12 do município de Foz do Iguaçu.

Em todas as edições contou com o auxílio da Itaipu na divulgação, realização e patrocínio do evento. A partir de 2008 o Instituto Federal de Foz do Iguaçu, através do Curso de Aquicultura tem colaborado na formação dos pescadores e auxílio na manipulação e boas práticas desta demanda. O Curso de Cozinha do mesmo Instituto, desde 2013 participa da Feira, desenvolvendo novos produtos de origem do pescado através da tecnologia de alimentos e gourmetzação, utilizando-se do pescado em novos pratos como uma alternativa na cadeia produtiva e consequente aumento de renda para o produtor rural.

A primeira Feira do Peixe Vivo foi realizada no ano de 2005, no Gramadão da vila A, não tendo registros do número correto de expositores e produtos comercializados. Nos anos seguintes, até 2010, a Feira foi realizada no estacionamento da antiga COBAL na Vila A.

No ano de 2011, as edições do evento possuem documentação comprobatória de seus dados. Em 2011, a Feira do Peixe Vivo foi realizada na Avenida das Araucárias, Extensão Cobal S/N Vila A e, a partir do ano de 2012 foi transferida para o Centro de Convivência do Idoso - CCI, na Praça da Bíblia, onde permaneceu até 2015. Por sua vez, em 2016 a feira foi transferida para o Parque Presidente no Centro de Tradições Gaúcha CTG Charrua, que segue até a edição atual.

Participaram inicialmente da Feira, 07 pescadores vinculados à Colônia Z12, 03 produtores de pescados ou peixarias, 05 pesque-pague, 17 produtores da agricultura familiar e 02 artesões, com um número máximo de 22 barracas, número esse que se alternou durante os anos. 


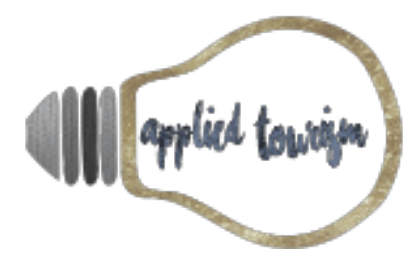

Volume 3, número 3, 2018, p. 37- 53

A venda de produtos caseiros esteve sempre aliada à Feira desde sua primeira edição. Dentre os produtores da agricultura familiar se encontra a APROFOZ, instituição sem fins lucrativo com o objetivo de desenvolver a agricultura familiar, orgânica, biodinâmica e sustentável, fundada em 03 de junho de 2006. Desde sua fundação a APROFOZ participa da feira; atualmente conta com 107 associados com diversas atividades.

Na Feira do Peixe Vivo, segundo os registros informados pela Secretaria Municipal da Agricultura já foram comercializadas as seguintes espécies de pescados: Carpa, Tilápia, Pacu, Piranha, Armado, Bagre, Corvina, Curimba, Pintado, Cat-fish, Tambaqui, Tucunaré e Cará. Estes pescados consistem nas principais espécies da região. Inicialmente a maioria dos peixes eram comercializados vivos, abatidos na feira para o público levar para a casa; com o passar dos anos perdeu-se essa característica e os pescados seguem sendo comercializado vivos, porém a comercialização em sua maioria é de frescos, congelados, defumados e filetados.

No decorrer dos 14 anos, a Feira sempre contou com alternativas de diversos produtos da agricultura familiar como: compotas, conservas, panificados, salames, geleias, mel, massas, hortaliças, ovos de pascoa, bombons, queijos, doce de leite, pamonha, sukiaki, vinhos, cerveja artesanal e produtos culinários à base de pescados como pastéis, bolinhos hamburguês, pizza, risotos, espetinhos entre outros, garantindo várias opções para os participantes.

Segundo Eduardo Espada, Secretário Municipal da Agricultura, em diversos mandatos distintos, o objetivo do evento sempre foi oferecer produtos e oportunidades de futuros negócios para os produtores rurais e, para a população, o direito de comprar produtos frescos, de qualidade, com a grande oportunidade de negociar diretamente com o próprio fornecedor.

Quadro 02 - Informativo Histórico de expositores na Feira do Peixe Vivo

\begin{tabular}{|c|c|c|}
\hline Ano & $\begin{array}{c}\text { Número de feirantes } \\
\text { (expositores) }\end{array}$ & $\begin{array}{c}\text { Número de barracas na } \\
\text { Feira }\end{array}$ \\
\hline 2011 & 18 & 20 \\
\hline 2012 & 20 & 21 \\
\hline 2013 & 19 & 21 \\
\hline 2014 & 19 & 21 \\
\hline 2015 & 12 & 12 \\
\hline 2016 & 20 & 20 \\
\hline 2017 & 16 & 18 \\
\hline 2018 & 10 & 12 \\
\hline
\end{tabular}

Fonte: Elaboração própria, com base nas informações coletadas na Secretaria Municipal da Agricultura de Foz do Iguaçu (2018). 


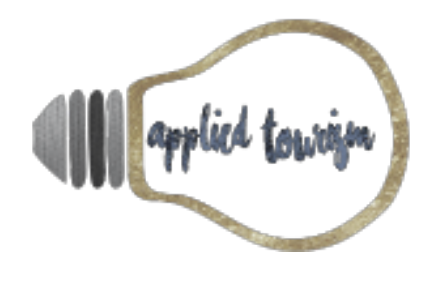

Percebe-se no quadro a ausência dos dados referentes aos anos de 2005 a 2010 pois, conforme já mencionado anteriormente, a Secretaria Municipal da Agricultura não dispõe destas informações. A diferença do número de expositores com relação ao número de barracas é justificada em razão de que os Pesque-pague mantém dois pontos, um destinado à comercialização do peixe e outro ponto destinado a comercialização de alimentos.

Com o passar dos anos o número de produtores decaiu e, uma justificativa para tal fato foi a diminuição da participação dos Pesque-pague, que alegam ter um alto movimento em suas propriedades na Semana Santa, resultando na falta de mão de obra para a participação na Feira.

\section{FEIRA DO PEIXE VIVO - EDIÇÃO 2018}

Durante a realização da Feira do Peixe Vivo - edição 2018 aplicou-se o questionário aos expositores, buscando responder ao objetivo da pesquisa. Os dados foram tabulados e analisados e são apresentados a seguir.

O primeiro bloco do questionário era destinado a traçar o perfil do expositor da Feira do Peixe Vivo. De acordo com o Quadro 02 apresentado na seção anterior, pode se observar que em 2018, a Feira contou com 10 expositores, dos quais apenas 08 responderam ao questionário, uma vez que os outros 02 expositores se tratavam dos Cursos de Aquicultura e Cozinha do Instituto Federal do Paraná - IFPR. Estes dois expositores tinham em suas barracas alunos dos respectivos cursos reproduzindo e comercializando pratos para arrecadação de fundos para suas comissões de formatura, não se caracterizando, portanto, como produtores da agricultura familiar.

Na edição 2018 da Feira do Peixe Vivo de Foz do Iguaçu estiveram presentes os seguintes expositores: 02 produtores rurais com a venda de pescado e produtos derivados do peixe, pertencentes à Colônia Z12; 02 pesque-pague e produtor de peixes e comercialização de alimentos; 01 produtor rural de pescados com tanque rede, com a comercialização de peixes nativos, venda de alimentos e derivados de pescados; o Clube de Mães com a venda de artesanato; a cooperativa de produtores rurais da agricultura familiar - APROFOZ, com a comercialização de produtos hortifruti e alimentação; a associação de pescadores do lado de Itaipu de Foz do Iguaçu - APPLIFI, com a comercialização de peixes nativos e venda de alimentos e derivados de pescado. O perfil dos expositores pode ser melhor visualizado no Gráfico 01. 


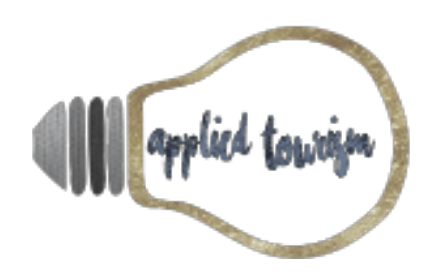

Volume 3, número 3, 2018, p. 37- 53

Gráfico 01 - Caracterização dos expositores presentes na Feira do Peixe Vivo - edição 2018.

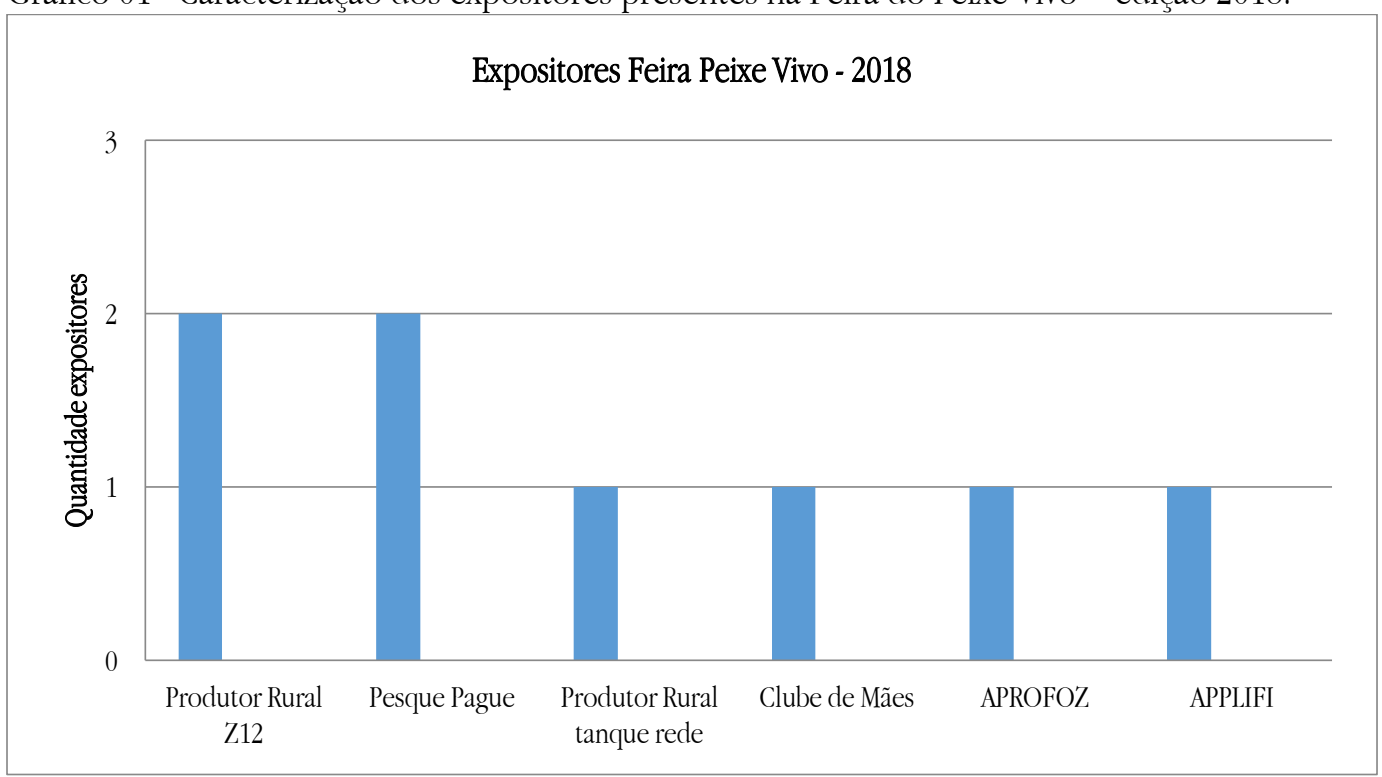

Fonte: Elaboração própria (2018).

O segundo bloco do questionário era dedicado a identificar o grau de importância e implementação atribuído pelos expositores aos constructos estabelecidos para análise da Feira enquanto propulsora do desenvolvimento rural sustentável em Foz do Iguaçu e são apresentados a seguir.

A Tabela 01, a seguir, apresenta os resultados obtidos para o constructo 'participação das organizações públicas e privadas no auxílio e gestão do evento' e seus respectivos indicadores, tanto para a importância de tal participação atribuída pelos entrevistados, como para a efetiva implementação desta participação.

Tabela 01 - Importância e implementação do constructo 'participação das organizações públicas e privadas no auxílio e gestão do evento' - Feira do Peixe Vivo

\begin{tabular}{l|l|c|c}
\hline \multicolumn{1}{c|}{ Indicadores } & N & $\begin{array}{c}\text { Média } \\
\text { (importância) }\end{array}$ & $\begin{array}{c}\text { Média } \\
\text { (implementação) }\end{array}$ \\
\hline $\begin{array}{l}\text { Participação, organização e auxílio da prefeitura } \\
\text { (secretaria da agricultura) }\end{array}$ & 8 & 5 & 3,6 \\
\hline Participação, organização e auxílio do sindicato rural & 8 & 3,7 & 3,6 \\
\hline $\begin{array}{l}\text { Participação, organização e auxílio da associação ou } \\
\text { cooperativa de produtores rurais. }\end{array}$ & 8 & 4,6 & 3,6 \\
\hline $\begin{array}{l}\text { Participação, organização e auxílio do evento enquanto as } \\
\text { entidades educacionais, universidade, escola técnica entre } \\
\text { outras. }\end{array}$ & 8 & 4,6 & 3,5 \\
\hline Valor Médio do constructo & - & 4,5 & 3,5 \\
\hline
\end{tabular}

Fonte: Elaboração própria (2018). 


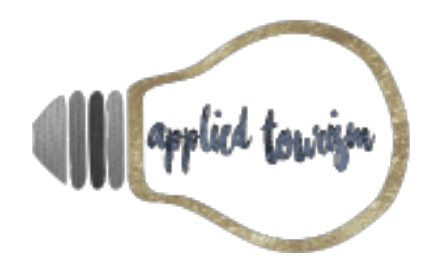

Volume 3, número 3, 2018, p. 37- 53

Analisando a Tabela 01 é possível verificar que o valor médio para todos os indicadores ficou superior com relação à importância percepcionada pelos entrevistados para o constructo 'participação das organizações públicas e privadas no auxílio e gestão do evento'. O indicador que maior pontuação recebeu, sendo considerado como extremamente importante pelos entrevistados foi a participação da Secretaria da Agricultura no auxílio e gestão da Feira, enquanto que o tido como de menor importância, considerado como medianamente importante foi a participação do Sindicado Rural. Na média atribuída para o constructo, a participação das organizações públicas e privadas no auxílio e gestão da Feira foi tido como bastante importante.

Ainda de acordo com a Tabela 01, com relação aos valores médios atribuídos para a implementação deste constructo, observa-se que todos os indicadores foram considerados como medianamente implementados, ou seja, aquém da importância atribuída para os mesmos, inclusive no indicador que menor valor médio obteve para a importância à ele atribuída. Isto demonstra uma insatisfação dos produtores quanto ao auxílio das organizações públicas e privadas na organização do evento em todos os níveis questionados: secretaria da agricultura, associações e entidades educacionais. Considera-se após a análise da média final do constructo que os produtores esperam uma maior participação das organizações públicas e privadas na organização e gestão do evento.

Os resultados obtidos para o constructo 'dimensão ambiental' e seus respectivos indicadores, tanto para a importância atribuída pelos entrevistados, como para a efetiva implementação deste constructo podem ser observadas na Tabela 02 a seguir.

Tabela 02 - Importância e implementação do constructo 'dimensão ambiental' - Feira do Peixe Vivo

\begin{tabular}{l|l|c|c}
\hline \multicolumn{1}{c|}{ Indicadores } & N & $\begin{array}{c}\text { Média } \\
\text { (importância) }\end{array}$ & $\begin{array}{c}\text { Média } \\
\text { (implementação) }\end{array}$ \\
\hline $\begin{array}{l}\text { Em relação ao tipo de produto oferecido pelo produtor } \\
\text { rural: qualidade do produto. }\end{array}$ & 8 & 4,7 & 4,4 \\
\hline $\begin{array}{l}\text { Em relação aos pratos gastronômicos: qualidade e higiene } \\
\text { de manipulação. }\end{array}$ & 8 & 4,5 & 4,2 \\
\hline Em relação ao local do evento: limpeza e organização. & 8 & 4,3 & 4,2 \\
\hline $\begin{array}{l}\text { Em relação ao local do evento: qualidade, adequação e bem } \\
\text { estar. }\end{array}$ & 8 & 4,1 & 4 \\
\hline $\begin{array}{l}\text { Cuidados em relação ao lixo produzido e contaminação ao } \\
\text { meio ambiente. }\end{array}$ & 8 & 4,2 & 3,8 \\
\hline Valor Médio do constructo & - & 4,4 & 4 \\
\hline
\end{tabular}

Fonte: Elaboração própria (2018).

De acordo com a Tabela 02 é possível observar que todos os indicadores, assim como a média do constructo 'dimensão ambiental' foram percepcionados como bastante importantes pelos entrevistados, sendo que o 


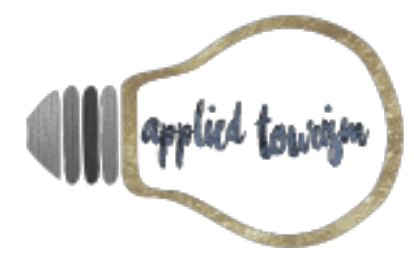

Volume 3, número 3, 2018, p. 37- 53

indicador que recebeu maior valor foi com relação a qualidade do produto oferecido pelo produtor rural e, o que recebeu menor valor foi com relação a qualidade, adequação e bem estar do local do evento.

Já com relação à implementação do constructo, ainda de acordo com a Tabela 02, verifica-se que a maioria dos indicadores foi percepcionado como bastante implementado, ficando apenas um indicador com um índice mediano, porém bem próximo ao superior e ainda, tendo o constructo um valor médio considerado como bastante implementado.

Este resultado demonstra a importância atribuída para a 'dimensão ambiental' nos indicadores questionados indicando que o produtor rural reconhece a importância dos cuidados ambientais, tanto na questão da produção, abate, comercialização e manipulação dos produtos oferecidos na feira, bem como o local para a realização desta. E ainda, em razão do valor médio atribuído para o constructo quanto a implementação, percebeu-se que o Centro de Tradições Gaucha (CTG) está preparado para receber o evento com qualidade para os feirantes e principalmente para os clientes e eventuais turistas que visitam a feira.

A Lei Municipal 3058, de 2005, criou o serviço de inspeção municipal de alimentos e produtos de origem animal SIMA/POA. Com essa lei, todos os produtores recebem um manual de procedimentos para registros agropecuários, que contem a declaração de abate, transporte e responsabilidade ambiental dos resíduos. Tal lei vem de encontro à 'dimensão ambiental' aqui tratada, demonstrando com os resultados da pesquisa que a mesma vem sendo colocada em prática na Feira do Peixe Vivo.

A Tabela 03, a seguir, apresenta os resultados obtidos para o constructo 'dimensão econômica' e seus respectivos indicadores, tanto para a importância da feira para a economia, atribuída pelos entrevistados, como para a efetiva implementação deste.

Tabela 03 - Importância e implementação do constructo ‘dimensão econômica' - Feira do Peixe Vivo

\begin{tabular}{l|l|c|c}
\hline \multicolumn{1}{c|}{ Indicadores } & $\mathrm{N}$ & $\begin{array}{c}\text { Média } \\
\text { (importância) }\end{array}$ & $\begin{array}{c}\text { Média } \\
\text { (implementação) }\end{array}$ \\
\hline $\begin{array}{l}\text { Contribuição econômica da realização do evento para o } \\
\text { produtor rural. }\end{array}$ & 8 & 4,6 & 3,6 \\
\hline $\begin{array}{l}\text { O lucro obtido no evento em relação ao faturamento anual } \\
\text { do agricultor. }\end{array}$ & 8 & 4,1 & 3,5 \\
\hline $\begin{array}{l}\text { Valores aplicados nos produtos oferecidos durante o evento } \\
\text { condizentes com a realidade. }\end{array}$ & 8 & 4,6 & 3,8 \\
\hline $\begin{array}{l}\text { Consumo do produto pelo público em geral durante o } \\
\text { evento. }\end{array}$ & 8 & 4,2 & 3,5 \\
\hline $\begin{array}{l}\text { Consumo do produto oferecido no evento durante o ano } \\
\text { inteiro }\end{array}$ & 8 & 4,6 & 3,2 \\
\hline Valor médio do constructo & - & 4,4 & 3,5 \\
\hline
\end{tabular}

Fonte: Elaboração própria (2018).

Cruz \& Fontana (2018). FEIRA DO PEIXE VIVO: Feiras Rurais enquanto Alternativa para a Agricultura Familiar e o Desenvolvimento Rural Sustentável. Applied Tourism, 3(3), 37- 53. 


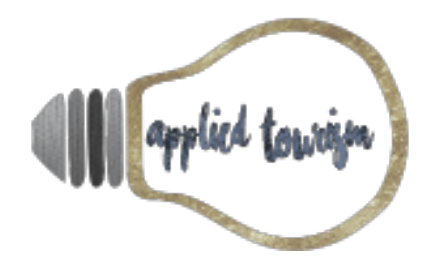

Volume 3, número 3, 2018, p. 37- 53

De acordo com a Tabela 03 verifica-se que os entrevistados consideraram o constructo 'dimensão econômica' como bastante importante em todos os seus indicadores, onde os indicadores relacionados à contribuição econômica da realização da Feira para o produtor rural, relacionados aos valores aplicados aos produtos durante o evento serem condizentes com a realidade e ainda, ao consumo do produto oferecido na Feira durante o ano todo foram os melhores avaliados e, embora dentro da faixa de bastante importante, mas com um valor médio menor, o indicador relacionado ao lucro obtido no evento em relação ao faturamento anual do produtor, foi considerado como o menos importante dentro da 'dimensão econômica'.

Ainda de acordo com a Tabela 03, observa-se que o valor médio percepcionado pelos entrevistados com relação à implementação do constructo ficou como medianamente implementado, embora o indicador relacionado aos valores aplicados nos produtos na Feira serem condizentes com a realidade ter sido o melhor avaliado, quase alcançando o limite para ser considerado bastante implementado. Com relação ao indicador com menor valor médio de implementação, observa-se que um dos indicadores com maior valor médio de importância para os entrevistados é o que encontra-se menos implementado, ou seja, o consumo oferecido durante a Feira o ano todo.

Com base nos valores apresentados na Tabela é possível afirmar que a Feira é de grande importância para a economia e lucratividade do produtor rural e consequentemente, o desenvolvimento rural sustentável. Porém, observa-se que sua efetiva implementação ainda está aquém do esperado pelos produtores rurais de Foz do Iguaçu. Verifica-se ainda que os valores aplicados na Feira sofrem um incremento pela demanda e oferta característica da época do ano, já que o evento ocorre durante a Semana Santa com consequente valorização do pescado.

A Tabela 04 , a seguir, apresenta os resultados obtidos para o constructo 'dimensão social' e seus respectivos indicadores, tanto para a importância da feira para a questão social e o desenvolvimento rural sustentável atribuída pelos entrevistados, como para a efetiva implementação deste constructo.

Tabela 04 - Importância e implementação do constructo ‘dimensão social’ - Feira do Peixe Vivo

\begin{tabular}{l|l|c|c}
\hline \multicolumn{1}{c|}{ Indicadores } & $\mathrm{N}$ & $\begin{array}{c}\text { Média } \\
\text { (importância) }\end{array}$ & $\begin{array}{c}\text { Média } \\
\text { (implementação) }\end{array}$ \\
\hline $\begin{array}{l}\text { Dimensão e participação deste evento para o } \\
\text { desenvolvimento do turismo rural. }\end{array}$ & 8 & 4,5 & 3,6 \\
\hline $\begin{array}{l}\text { Relação do evento e oportunidade de novos negócios para o } \\
\text { produtor rural. }\end{array}$ & 8 & 4,6 & 3,2 \\
\hline $\begin{array}{l}\text { Impacto do evento na sociedade e na cultura do consumo } \\
\text { destes produtos. }\end{array}$ & 8 & 4,3 & 3,6 \\
\hline Efetiva participação do produtor rural no evento. & 8 & 4,3 & 2,7 \\
\hline
\end{tabular}

Cruz \& Fontana (2018). FEIRA DO PEIXE VIVO: Feiras Rurais enquanto Alternativa para a Agricultura Familiar e o Desenvolvimento Rural Sustentável. Applied Tourism, 3(3), 37- 53. 


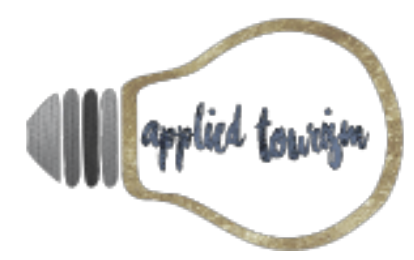

Volume 3, número 3, 2018, p. 37- 53

\begin{tabular}{l|l|c|c|c}
\hline \multicolumn{1}{c|}{ Indicadores } & $\mathrm{N}$ & $\begin{array}{c}\text { Média } \\
\text { (importância) }\end{array}$ & $\begin{array}{c}\text { Média } \\
\text { (implementação) }\end{array}$ \\
\hline $\begin{array}{l}\text { O evento enquanto contributo para a fixação do agricultor no } \\
\text { campo. }\end{array}$ & 8 & 4,2 & 2,8 \\
\hline $\begin{array}{l}\text { Criação de novos produtos gastronômicos para o } \\
\text { desenvolvimento sustentável do produtor rural. }\end{array}$ & 8 & 4,6 & 4,1 \\
\hline Valor médio do constructo & - & 4,4 & 3,3 \\
\hline
\end{tabular}

Fonte: Elaboração própria (2018).

Com base na Tabela 04 é possível observar que os valores atribuídos para a importância da 'dimensão social' em todos os seus indicadores é maior que a efetiva implementação dos mesmos na Feira, ou seja, o constructo é considerado bastante importante e medianamente implementado. Embora a média para a implementação tenha alcançado o valor correspondente a estar medianamente implementado, dois indicadores tiveram suas médias consideradas como pouco implementados, sendo eles, o indicador referente à efetiva participação do produtor rural no evento e ainda, a contribuição da Feira para a fixação do agricultor no campo. Esse resultado vem de encontro ao perfil dos expositores detectado com esta pesquisa, onde verifica-se que apenas cinco dos oito expositores entrevistados são efetivamente produtores rurais (Gráfico 01) vivendo no campo.

Analisando a Tabela 04 é possivel afirmar que o produtor rural e agricultor familiar o reconhecem a importância da participação nos eventos, como feiras rurais, pois consiste numa grande oportunidade para o desenvolvimento rural sustentável, colaborando com a proximidade do urbano com o rural, proporcionando oportunidades de realizações de negócios futuros. Ainda é possível verificar que para os produtores, a realização da Feira do Peixe Vivo não está contribuindo para a fixação do produto no campo, como acreditam ser importante. Porém, com o passar dos anos a Feira cresceu em desenvolvimento de produtos gastronômicos e isso tornou uma grande alternativa para o produtor fazer frente a outros produtos e conquistar o mercado.

Com relação aos valores médios atribuídos para a importância e implementação do constructo 'relação dos produtos comercializados' e seus respectivos indicadores, os mesmos encontram-se descritos na Tabela 05, a seguir.

Tabela 05 - Importância e implementação do constructo 'relação dos produtos comercializados' - Feira do Peixe

\begin{tabular}{l|l|c|c}
\hline \multicolumn{1}{c|}{ Indicadores } & $\mathbf{N}$ & $\begin{array}{c}\text { Média } \\
\text { (importância) }\end{array}$ & $\begin{array}{c}\text { Média } \\
\text { (implementação) }\end{array}$ \\
\hline Disponibilidade de encontrar o produto fora do evento. & 8 & 4,3 & 3,8 \\
\hline Relação do produto regional com a agricultura familiar & 8 & 4 & 3,5 \\
\hline $\begin{array}{l}\text { Relação do produto ofertado e registro nos órgãos competentes, } \\
\text { CIF, vigilância. }\end{array}$ & 8 & 4,3 & 3,8 \\
\hline Disponibilidade quantitativa do produto no evento & 8 & 4,6 & 3,8 \\
\hline Variedade produtos ofertados no evento. & 8 & 4,3 & 4,2 \\
\hline Valor médio do constructo & - & 4,3 & 3,8 \\
\hline
\end{tabular}

Fonte: Elaboração própria (2018). 


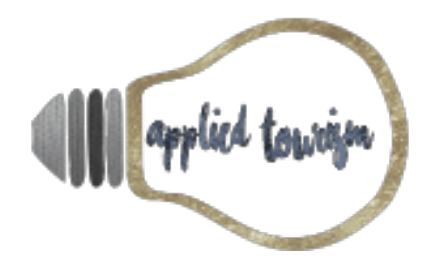

Volume 3, número 3, 2018, p. 37- 53

Analisando a Tabela 05 observa-se que igualmente às demais dimensões, os valores médios atribuídos para a importância do constructo 'relação dos produtos comercializados' é maior do que sua efetiva implementação na Feira do Peixe Vivo, sendo que todos os indicadores do constructo foram considerados como bastante importantes. Embora o valor médio para a implementação do constructo tenha sido considerado como medianamente implementado, o indicador relacionado à variedade de produtos ofertados no evento foi considerado bastante implementado pelos entrevistados.

Ainda de acordo com a Tabela 05 é possível deduzir que para o produtor, o consumidor que participa da feira encontra os produtos ofertados durante o ano todo, pois com as certificações já conquistadas facilitam a comercialização em outros locais, como supermercados e centros de distribuições. Percebe-se, portanto, que a relação da agroindústria e manutenção da agricultura familiar no campo está vinculada com a possibilidade de agregação de valor de seus produtos que possibilita uma maior geração de renda e um produto final competitivo e de qualidade.

Durante a Feira do Peixe Vivo de 2018, os produtores da agricultura familiar que participaram da Feira registraram junto o município, através da Nota de Produtor Rural o montante de valor de $\mathrm{R} \$ 147.761,00$ sendo que tal valor consiste no total das vendas e comercialização de todos os produtos oferecidos (SMAFI, 2018).

Para uma melhor visualização da pontuação média atribuída à importância e implementação dos constructos avaliados pelos expositores durante a Feira do Peixe Vivo de 2018, os dados são apresentados no Gráfico 02, a seguir.

Gráfico 02 - Importância e implementação dos constructos analisados pelos expositores presentes na Feira do Peixe Vivo - edição 2018.

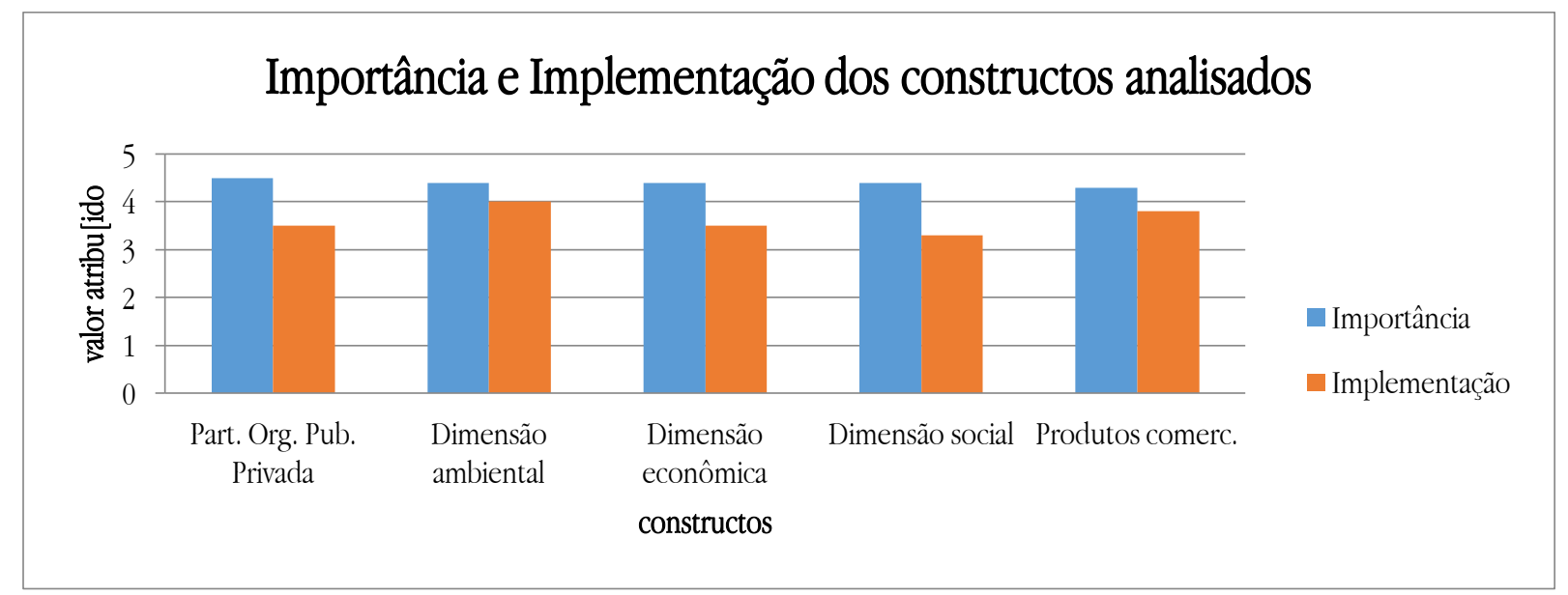

Fonte: Elaboração própria (2018). 


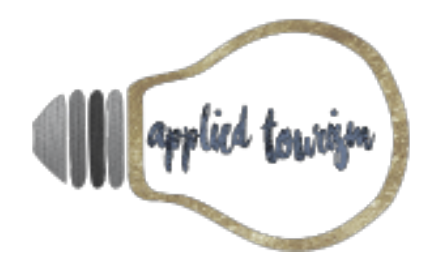

Volume 3, número 3, 2018, p. 37- 53

De acordo com o Gráfico 02 é possível observar que todos os constructos foram considerados como bastante importantes pelos entrevistados enquanto que somente o constructo 'dimensão ambiental' obteve a mesma percepção com relação à implementação, sendo que as demais foram considerados como medianamente implementadas. Isto demostra que os organizadores da Feira precisam atentar para os pontos com implementação abaixo da importância atribuída para melhorar o desempenho do evento para que o mesmo venha contribuir cada vez mais para o desenvolvimento rural sustentável e a agricultura familiar no municipio de Foz do Iguaçu.

Sendo assim, com base nos resultados ora apresentados destacando a importância dos constructos aqui propostos para uma análise de feiras enquanto alternativa para a agricultura familiar e o desenvolvimento rural sustentável, considera-se viável a replicabilidade de tal instrumento em outros eventos de semelhante teor. Acredita-se que tais pesquisas possam demonstrar, a exemplo desta, a capacidade de tais atividades (feiras rurais) para o fortalecimento da economia do pequeno produtor rural e consequentemente, maior interação do espaço rural e urbano.

\section{CONSIDERAÇÕES FINAIS}

Nesta economia global onde centros urbanos concentram parte da população e as principais atividades econômicas, o desenvolvimento rural sustentável, e seu principal sujeito o pequeno agricultor, necessita de alternativas e condições que o tornem competitivo neste contexto.

Nestas condições sugere-se o turismo rural, como feiras e eventos como estratégias e diretrizes para desenvolver um território rural viável envolvendo aspectos econômicos, socioculturais e ambientais, aspectos esses considerados como pilares do desenvolvimento e sustentabilidade rural.

A Feira do Peixe Vivo de Foz do Iguaçu vem se apresentando como uma alternativa de negócio para a agricultura familiar principalmente frente aos anos de crise que assola o país. Números expressivos de venda foram detectados na edição de 2018, que incrementam a renda e representam uma parcela significativa dos ganhos anuais destes pequenos produtores.

O estudo da Feira do Peixe Vivo demonstrou ser este um evento já consolidado no município. Porém, para que este evento siga com números expressivos de participação de produtores, comercialização e principalmente adesão do público em geral, é necessário um esforço conjunto das entidades públicas e privadas organizadoras, como a Itaipu, Secretaria Municipal da Agricultura e Instituições de Ensino, realizando um planejamento estruturado anual com apoio ao pequeno produtor, desde o momento do manejo produtivo, despesca com 


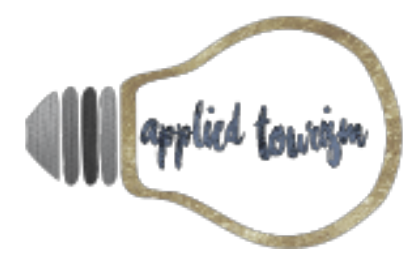

Volume 3, número 3, 2018, p. 37- 53

qualidade, inovação e tecnologia na criação de novos produtos e condições adequadas de comercialização para o produtor e consumidor terem as condições de fornecerem e consumirem os produtos ofertados no decorrer do ano, em outros eventos do mesmo porte ou novos locais apropriados.

Sendo assim, esta pesquisa que teve como principal objetivo analisar a Feira do Peixe Vivo de Foz do Iguaçu enquanto propulsor do desenvolvimento rural sustentável, utilizando-se de informações documentais e entrevistas em forma de questionário junto aos expositores da edição de 2018, obteve êxito nos resultados encontrados, observando que mesmo com um pequeno número de expositores produtores rurais e agricultores familiares, o evento pode ser considerado como uma alternativa de negócio para a agricultura familiar e o turismo rural, agindo como propulsor para o desenvolvimento rural sustentável, uma vez que gera renda e amplia a oportunidade de oferta dos produtos comercializados, trazendo não somente retorno financeiro, como também social e ambiental para o pequeno produtor rural.

E finalmente, este artigo, veio contribuir com a academia através da pesquisa multidisciplinar e extensionista, (nas áreas do desenvolvimento rural, agricultura familiar e turismo rural) na qual, estabelece alternativas econômicas, sociais, ambientais e mercadológicas para os diversos produtores e feirantes envolvidos no evento. Por consequente abre caminho para novas pesquisas que, por sua vez, busquem criar estratégias para a sustentabilidade e permanência do homem no campo.

\section{REFERÊNCIAS}

Carneiro, M. J. (2005). Pluriatividade da agricultura no Brasil: uma reflexão crítica. In: I Seminário Agricultura Familiar e Desenvolvimento Rural. Porto Alegre: NEAD/PGDR/UFRGS.

Flores, M. (2002). Assistência técnica e agricultura familiar. In: Lima, D. M. A.; Wilkinson, J. (Orgs). Inovação nas tradições da agricultura familiar. Brasília Cnpq,/Paralelo, p.347-360.

Fontana, R. F.; Dencker, A. F. M. (2006). Turismo Rural: desencontros de uma realidade. In: IV SeminTUR Seminário de Pesquisa em Turismo do MERCOSUL . Caxias do Sul, RS, Brasil.

FortinN, M. F. (1996). O processo de investigação, da concepção à realização. Montreal: Ed. Decarié.

Froehlich, J. M.; Diesel. V. (Orgs). (2006). Desenvolvimento Rural: tendências e debates contemporâneos. Ijuí: Ed Unijui.

Georgin, J. e Scherer, C. B. (2015). Festas Rurais: Mídia, Dimensão festiva e Impacto Social em Duas Pequenas Comunidades do Rio Grande do Sul. Revista Monografias Ambientais - REMOA, 14(1), Santa Maria,UFSM, p.115-122.

Gil, A.C. (2002). Como elaborar projetos de pesquisas. São Paulo: Edição Atlas. 


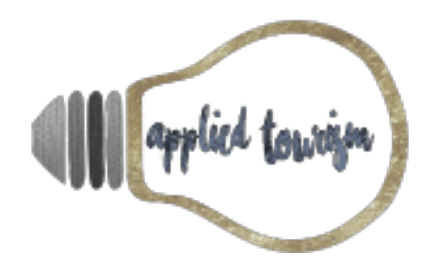

Volume 3, número 3, 2018, p. 37- 53

Lima, D. A.; ILKINSON, J. (Orgs). (2002). Inovações nas tradições da agricultura familiar. Brasília CNPq/ Paralelo.

Matias, M. (2001). Organização de eventos: procedimentos e técnicas. São Paulo: Manole.

Nagildo, F.; Fontana, R. F. (2016). Captação de Eventos: Estratégia Fortalecedora de Destinos Turísticos. In: Anais Ciclo Internacional de Atividades Hoteleiras, VII CIAH. Foz do Iguaçu.

SemEM, A. (2000). Desenvolvimento como liberdade. São Paulo: Companhia das Letras.

SMAFI, Secretaria Municipal da Agricultura. (2018, maio). Entrevista e consulta documental realizada pelos autores.

Souza, M.; Elesbão I. (Orgs). (2011). Turismo Rural: Iniciativas e inovações. Porto Alegre: Ed. da UFRGS.

Wanderley, M. N. B. (2002). Territorialidade e ruralidade no Nordeste: por um pacto social pelo desenvolvimento rural. In: Sabourin E.; Teixeira, O. A. (ed.) Planejamento e desenvolvimento dos territórios rurais: conflitos, controvérsias e experiências. Embrapa Informação Tecnológica, Brasília, p. 39-52. 